\title{
Las tendencias migratorias entre América Latina y Europa durante las últimas dos décadas
}

\author{
- The Migration Trends between Latin America and Europe \\ in the last two decades -
}

\begin{abstract}
Today migration is an increasingly important issue concerning international and interregional relations. In the last decades, immigration from Latin America to Europe was considerable, but as a result of the economic crisis in the European Union the tendency has been changed. On the contrary, the number of Europeans living and working in Latin America has increased, typically in sectors where skilled labor is needed. At the political level there is an effort for further cooperation between the two regions concerning migration. The document „Bases for structuring the EU-LAC Dialogue on Migration” of 2009 includes the objectives and major activities on the subject.
\end{abstract}

KeYwords Latin America, European Union, remittances, return migration, migration and development.

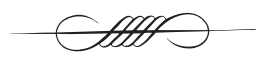

\section{Introducción general}

América Latina y Europa son aliados y están unidos por fuertes lazos históricos, culturales y económicos, por eso hace siglos hay también intercambio de personas importante entre los dos territorios culturales. En este estudio primero presento brevemente la historia de la migración entre América Latina y Europa. Después analizo las tendencias migratorias de hoy, y por último las relaciones migratorias bilaterales entre América Latina y la Unión Europea.

Ante todo se necesita aclarar ¿qué entendemos sobre los movimientos migratorios? Según la Organización Internacional para las Migraciones(OIM) la definición dela migración es el siguiente: „Término genérico que se utiliza para describir un movimiento de personas en el que se observa la coacción, incluyendo la amenaza a la vida y su subsistencia, bien sea por causas naturales o humanas. (Por ejemplo, movimientos de refugiados y de desplazados internos, así como personas desplazadas por desastres naturales o ambientales, desastres nucleares o químicos, hambruna o proyectos de desarrollo)."(ORGANIZACIÓN INTERNACIONAL PARA LAS MigraCiOnes 2013) El motivo más general de desplazamiento de las personas es económico, por eso hoy día los movimientos migratorios son circulares (temporales). Después de ganar suficiente dinero en el extranjero, muchas personas regresan a su país de origen. Debido al mercado de trabajo 
que se ha internacionalizado en las últimas décadas, el movimiento humano también ha sido significativo. Los países receptores deben conducir el mercado laboral teniendo en cuenta las necesidades de los habitantes locales, y de los foraneos también. Sin embargo, la migración debe ser vista como un fenómeno con potencial económico, social y cultural igual manera en los países de origen y destino.

\section{Panorama histórico}

Desde la época colonial,existe un gran flujo de mercancías y herramientas entre el Nuevo Mundo y Europa, también intercambios de caracter cultural, político y económico. América Latina y el Caribe fueron regiones caracterizadas por ser destino de importantes flujos migratorios principalmente desde el Imperio Español y del Imperio Portugués. A finales del siglo XIX y comienzos del XX, la situación en Europa se caracterizó por la emigración masiva; colas interminables en los puertos con gente ansiosa por dejar atrás una Europa empobrecida y violenta. Este período limitado por las guerras mundiales y la Gran Depresión de 1930 vio una migración de personas que fue el detonante de una incipiente globalización.

Esta tendencia se mantuvo constante hasta la segunda mitad del siglo XX, momento en que los países de América Latina comenzaron a marcar saldos migratorios negativos. ${ }^{1}$ Para el año 2000, existían 21 millones de migrantes internacionales nacidos en la región, lo cual constituía en $11 \%$ del total a nivel mundial. (CEPAl 2006)

1 El saldo migratorio es el balance que existe entre la inmigración http://es.wikipedia.org/wiki/ Inmigraci\%C3\%B3ny la emigración en un determinado lugar. Cuando el saldo migratorio es positivo, la población aumenta; cuando el saldo migratorio es negativo, la población disminuye.
En relación con América Latina, desde una mirada global, estudios demográficos demuestran que el volumen del flujo migratorio hacia los países industrializados ha ido creciendo y que la región se ha convertido en „exportadora" de población durante las últimas décadas del siglo XX. (Novick 2013) Gracias a este nivel de migración, los envíos de las remesas en la década del 2000 contribuyó al crecimiento económico e hizó más eficiente el combate contra la pobreza. Las remesas también han incidido sobre las condiciones de vida de los miembros de los hogares migrantes en países exportadores de fuerza de trabajo -mujeres e hijos en su mayoría- y sobre las condiciones de vida de los remitentes. (CoRTÉs 2011)

\section{La migración de América Latina en el siglo XXI}

Un factor muy importante de la migración es lo económico. En los últimos años podemos ver el resurgimiento de la migración desde Europa a América Latina a causa dela crisis económica en Europa. La naturaleza de esta migración es bastante distinta a la anterior. La inmigración de hoy no es masiva ni popular y los inmigrantes son principalmente licenciados con estudios de postgrado, que dominan un minimo de dos o tres idiomas. Actualmente, el mercado europeo se encuentra saturado de profesionales,y la pequeña oferta intensifica la competencia. Las malas condiciones de trabajo actuales de Europa llevan a los europeos cualificados a dejar sus países para poder realizar sus proyectos de vida. En contrario, en América Latina ocurre lo siguiente: hay relatívamente mucha oferta de empleo, pero no hay suficiente gente cualificada para los puestos. Ahora los prioridades de inversión se dan a los países emergentes en vez de a los desarrollados. Por eso los salarios son también más altos en los países emergentes. De hecho en América Latina el desempleo es altopara la gente sin 
estudios, o poco calificado, pero muy bajo para personas calificadas. Los latinoamericanos quiénes salieron de sus países por distintos motivos, ahora están regresando a su tierra. El caso de los inmigrantes latinoamericanos con menos recursos es distinto, ellos no vuelvan a sus países de origen.

La mayoría de los inmigrantes europeos en América Latina son españoles, franceses y portugueses. Los destinos más preferidos son Brasil, México, Colombia, Chile, Argentina y Perú. Estos países tienen prioridad debido a la calidad de vida local, políticas macroeconómicas, seguridad, nivel de sueldo y clima apropiado para los negocios. (BANCHón 2011)

Por otro lado en el flujo migratorio de América Latina hacia Europa hay un parón. Las razones son las mismas: la crisis en Europa, el alto desempleo y las perspectivas de crecimiento económico en América Latina. Incluso los inmigrantes latinoamericanos retornan a sus países de origen porque ya no encuentran las oportunidades laborales que vinieron buscando en el „Viejo Continente”. Por ejemplo en España esta emigración estuvo compensada hasta los finales de 2010 por la superior entrada de nueva inmigración que, pese a la crisis económica, ha seguido llegando, pero en 2011 las salidas ya superaron las llegadas. El aumento

Transporte de mercancías. Peru, Piura * La foto fue tomada por Gábor Molnár en 2011.

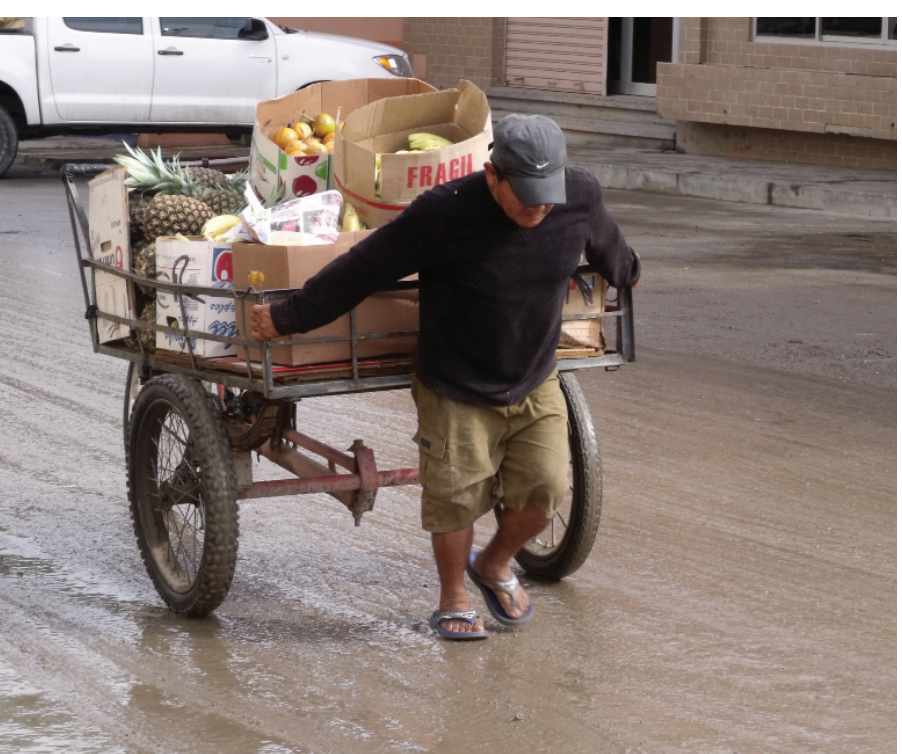

de españoles en el extranjero parcialmente resulta de esa migración de retorno de inmigrantes nacionalizados españoles. (GoNZÁLEZ ENRÍQUEZ 2012)

\section{Regulaciones de migración internacio- nal y cooperación entre la UE y ALC}

Los países de América Latina y la Unión Europea cultivan sus relaciones en una forma controlada y disfrutan de una relación privilegiada desde 1999, cuando establecieron una associación estrategica en Río De Janeiro. Cooperan estrechamente en el plano internacional y mantienen un intenso diálogo político a todos los niveles - regional, subregional (América Central,el Caribe,países andinos y Mercosur) y, cada vez más, a nivel bilateral. (Unión Europea Acción Exterior 2013) Durante los últimos años la migración internacional se ha convertido en un tema cada vez más importante para éstas relaciones entre las dos regiones. El proyecto „Fortalecimiento del diálogo y de la cooperación entre la Unión Europea (UE) y América Latina y el Caribe (ALC) para el establecimiento de modelos de gestión sobre migración y politícas de desarrollo" es promovido por la Unión Europea con el objetivo de apoyar el intercambio permanente de información y buenas practicas entre los países y las regiones. La Organización Internacional para las Migraciones también participa en el proyecto. El proyecto se compone de tres partes:

Datos Migratorios: Fortalecimiento de la recolección de datos migratorios.

Migración y Empleo: Construcción de capacidades para consolidar la gestión de las migraciones.

Remesas y Políticas de Desarrollo: Fortalecimiento institucional para promover las inversiones productivas de remesas. (Migración EU-LAC 2014.) 
El plan de acción CELAC ${ }^{2}$-UE 2013-2015 también contiene un capítulo sobre la migración. Los principales objetivos en este ámbitó son los siguientes:

„1) Mejorar la cooperación bi-regional mediante la identificación de desafíos y oportunidades comunes que requiren soluciones comunes;

2) Construir una base más sólida para la migración UE-ALC, con el fin de entender mejor sus realidades;

3) Atender las sinergias positivas entre migración y desarrollo, así como atender la migración regular e irregular y otras cuestiones relacionadas;

4) Promover el respeto completo de los derechos humanos de los migrantes." 3

Se puede constatar que América Latina y el Caribe y la Unión Europea ya tienen una estrategia migratoria bien desarrollada. En el Cumbre de Lima en 2008 los países de UE-ALC se pusieron de acuerdo y en 2009 crearon el documento „Bases para estructurar el diálogo UE-ALC sobre migración”. Este documento constituye el marco de las políticas migratorias, establece sus principios, objetivos y responsabilidades. Los objetivos establecidos de cooperación en el ámbito de migración son los siguintes: „determinación de desafíos comunes y ámbitos de cooperación mutua, así como la elaboración de una base más sólida de documentación en materia de migración UE-ALC para entender mejor la realidad del fenómeno, basándose en el principio de responsabilidad compartida, en el refuerzo del compromiso y en la voluntad de ambas Partes de debatir las cuestiones relacionadas con la migración."' Las Partes acordaron que van a compartir mayor información sobre los avances de la política de migración y las prácticas idóneas en ambas regiones, para identificar los ámbitos de interés

2 Comunidad de Estados Lationoamericanos y Caribeños

3 Eu-Celac Action Plan 2013-2015. Council of the European Union, Santiago, 2013.

4 Bases para estructurar el diálogo UE-ALC sobre migración. Bruselas, 2009. 3. mutuo que requieren soluciones cooperativa en cuestiones específicas. El documento también analiza el diferente tratamiento de inmigración irregular y regular.

\section{Cierre}

El flujo migratorio entre América Latina y Europa es un fenomeno muy amplio y diverso. En este breve estudio solamente demostré las tendencias actuales más importantes en relación de la migración entre las dos regiones. En el futuro se puede hacer una investigación más profunda sobre este tema. Es posible investigar por ejemplo los movimientos migratorios de la Europa del Este hacia América Latina también. Debido a la crisis económica mundial que ha tenido una gran influencia en los países de la Unión Europea y al desarollo dinámico de la economía en los países de América Latina, las tendencias migratorias han cambiado. Según las estatísticas el número de los inmigrantes europeos van aumentando en América Latina (aunque no es inmigración masiva), principalmente en Brasil, México, Colombia, Chile y Argentina, dónde hay gran auge económico. Se puede observar una migración de retorno de los inmigrantes latinoamericanos en Europa, porque ya no existen tantas posibilidades laborales.Es importante mencionar que América Latina y la Unión Europea también tienen una relación considerable en el nivel político sobre la migración. En los últimos años en los Cumbres UE-LAC se debatió sobre la migración interregional, y las bases para una política migratoria ya han sido elaboradas. Los lazos históricos y culturales siempre han existido entre los países latinoamericanos y caribeños y las naciones de la Unión Europea, por ello la migración no es un fenomeno nuevo. La pregunta gira en torno a si las dos regiones pueden formar su política migratoría de manera que contribuya al desarollo económico, social y cultural. 


\section{NETGRAFÍA}

BANCHÓn, Mirra (2011): UE y América Latina: ¿cambia de direcciónla emigración? DeutscheWelle24denoviembre.http://www.dw.de/ue-y-am\%C3\%A9ricalatina-cambia-de-direcci\%C3\%B3n-la-emigraci\%C3\%B3n/a-15554749 (Última consulta: 14 de mayo de 2014 08.47)

Bases para estructurar el diálogo UE-ALC sobre migración. Bruselas, 2009. http://www.europarl.europa.eu/meetdocs/2009_2014/documents/dlat/dv/ basis/basises.pdf (Última consulta: 14 de mayo de 2014 08.48)

Cepal Migración Internacional, Derechos Humanos y Desarrollo en América Latina y el Caribe. Trigésimo primer periodo de sesiones, Montevideo, Uruguay, 20 al 24 marzo de 2006. p. 23. http://www. eclac.org/publicaciones/xml/8/26608/LCW98migracion.pdf (Última consulta: 14 de mayo de 2014 08.48)

Comunidad de Estados Lationoamericanos y Caribeños http://www.celac.gob.ve/ (Última consulta: 14 de mayo de 2014 08.49)

Cortés, Rosalía (2011): Migración y Remesas. Nexos América Latina-Europa. En la Revista Bianual Pensamiento Iberoamericano 2011.1. Las relaciones triangulares Estados Unidos, Unión Europea y América Latina. http://www.pensamientoiberoamericano.org/xnumeros/PensamientoIbero8. pdf (Última consulta: 14 de mayo de 2014 08.50)

Eu-Celac Action Plan 2013-2015. Council of the European Union, Santiago, 2013. http://www.consilium.
europa.eu/uedocs/cms_Data/docs/pressdata/EN/ foraff/135043.pdf (Última consulta: 14 de mayo de 2014 08.50)

González EnríQuez, CARMen (2012): La emigración desde España, una migración de retorno. Real Instituto Elcano. http://www.realinstitutoelcano. org/wps/portal/rielcano/contenido?WCM_GLOBAL_CONTEXT=/elcano/elcano_es/zonas_es/ ari4-2012 (Última consulta: 14 de mayo de 2014 08.51)

Migración UE-ALC. Fortalecimiento del diálogo y de la cooperación entre la Unión Europea (UE) y América Latina y el Caribe (ALC) para el establecimiento de modelos de gestión sobre migración y politícas de desarrollo http://www.migracion-ue-alc.eu/ index.php/es-ES/el-proyecto (Última consulta: 14 de mayo de 2014 08.51)

Novick, Susana (2008): Las migraciones en América Latina. http://biblioteca.clacso.edu.ar/ar/libros/ grupos/novick/novick.pdf (Última consulta: 14 de mayo de 2014 08.52)

Organización Internacional para las Migraciones

http://www.iom.int/cms/es/sites/iom/home/ about-migration/key-migration-terms-1. html\#Migraci\%C3\%B3n (Última consulta: 14 de mayo de 2014 08.52)

Relaciones de la UE con América Latina y el Caribe. Unión Europea Acción Exterior http://eeas.europa. eu/lac/index_es.htm (Última consulta: 14 de mayo de 2014 08.54)

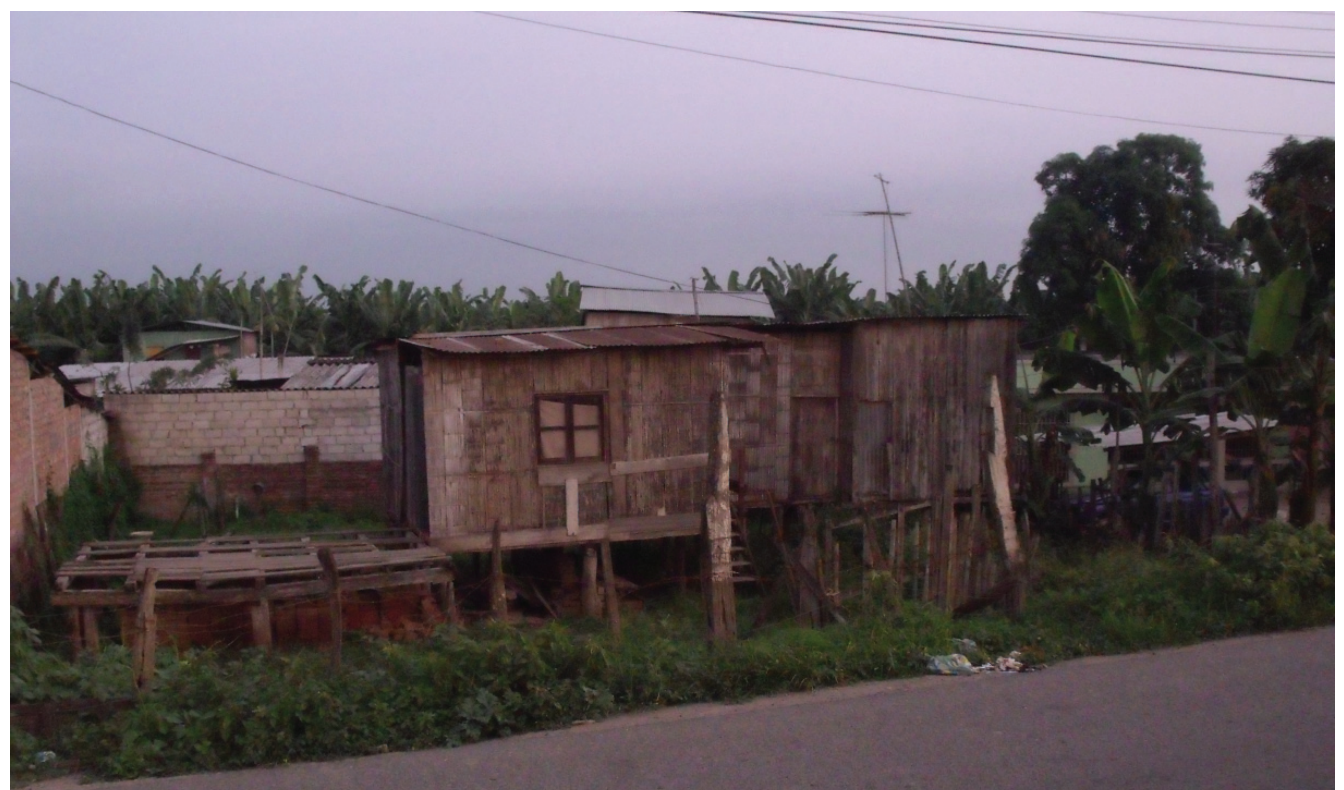

